\title{
Legitimidad y credibilidad en el sistema de AFP: Algo más que gobierno corporativo
}

Eduardo Abarzúa C.

Ph.D. en Ciencias del Trabajo, Universidad Católica de Lovaina

Director del Departamento de Gestión y Negocios (FEN-UAH) y miembro del Consejo de Alta Dirección Pública

Este artículo discute algunas de las soluciones técnicas que se proponen para mejorar los sistemas de pensiones, en particular aquellas que se enfocan en el diseño institucional y la participación de propietarios. Se sostiene que cualquier rediseño viable del sistema deberá combinar la eficiencia económica con la legitimidad social. En este contexto, se problematiza la propuesta de entregar atribuciones a los propietarios de los fondos de pensiones como contraparte de las administradoras de fondos de pensiones. Un sistema de pensiones será durable en la medida que sea reconocido y aceptado como lícito y genuino por el conjunto de los actores de nuestro país.

\section{Antecedentes}

La discusión respecto de la institucionalidad y gobernabilidad de los sistemas de pensiones se ha puesto en la palestra a nivel mundial en el marco del debilitamiento de los fondos de pensiones como consecuencia de las crisis económicas internacionales y las bajas tasas de interés. En efecto, se busca ponderar el impacto de la gobernanza del sistema sobre el desempeño y sus elecciones de inversión. En nuestro país, esta dimensión de gobernanza ha sido un factor omitido en el análisis y recién ahora el grupo Mejores Pensiones para Chile propone de crear un Comité de Propietarios de Fondos en cada AFP (Grupo Mejores Pensiones para Chile, 2016). Al mismo tiempo, aparecen algunas iniciativas desde el sistema ofreciendo Habitat y Cuprum la creación de un comité y asamblea de afiliados que debutaron durante 2017.

\section{Institucionalidad y representación de los propietarios}

El Sistema de Pensiones está regulado y fiscalizado por la Superintendencia de Pensiones, estando la participación de propietarios considerada a nivel macro en una estructura asesora denominada Comisión de Usuarios del Sistema de Pensiones. Esta instancia informa a la Subsecretaría de Previsión Social respecto de evaluaciones que realiza sobre el funcionamiento del sistema de pensiones y propone estrategias de educación y difusión. La Comisión está integrada por un representante de los trabajadores, uno de los pensionados, uno de las instituciones públicas, uno de las entidades privadas del sistema de pensiones y un académico universitario que la preside. La Comisión fue recién incorporada en la reforma del año 2008, luego de la propuesta hecha al respecto por la Comisión Marcel.

*Email de contacto: eabarzua@uahurtado.cl. 
Sin embargo, la ley promulgada omitió atribuciones interesantes que se proponían para este Comité de Usuarios: expresar la opinión de los actores del sistema previsional sobre su funcionamiento, monitorear el cumplimiento de las metas de la reforma, conocer y emitir una opinión respecto a los estudios del sistema (actuariales, de opinión de usuarios, comparativos sobre costos de administración), evaluaciones externas sobre el sistema previsional y proyectos de reforma, entre otros (Consejo Asesor Presidencial para la Reforma Previsional, 2006).

A nivel de operación del sistema, existen las administradoras de fondos de pensiones que entre otras funciones realizan tareas de recaudación de cotizaciones previsionales, gestiones de cobranza en caso de no pago de estas cotizaciones, inversión de los ahorros previsionales, trámites de pensión y pago de pensiones. Su estructura corporativa es clásica, con un directorio y sus comités (inversiones y solución de conflictos de interés, riesgo y auditoría). En este nivel nuestro sistema de pensiones no contempla la participación de propietarios.

Las administradoras invierten en las sociedades anónimas, siendo la inversión en acciones locales en el año 2016 el $7,9 \%$ del total de los fondos, equivalente a US\$13.229 millones. Este tamaño de inversión limita la posibilidad de que los Fondos puedan por sí solos elegir un director en una sociedad, no así si actúan conjuntamente. Es así como en abril del 2016, en 22 de las 30 juntas con elección de directorio a que concurrieron obligatoriamente los Fondos, la participación conjunta de ellos, sumado el apoyo de otros minoritarios, permitió elegir un total de 30 directores titulares y 4 suplentes (Superintendencia de Pensiones, 2016). Para ser elegible por los Fondos de Pensiones como director en las sociedades anónimas donde éstos puedan invertir se debe estar inscrito en el Registro de Directores de la Superintendencia de Pensiones y reunir con una serie de requisitos experiencia y competencias profesionales. Al momento de escribir este artículo la página web de la Superintendencia de Pensiones registra 350 directores inscritos, siendo la mayoría ingenieros de Universidad Católica y la Universidad de Chile.

Al examinar la estructura de gobierno de nuestro sistema de pensiones, llama la atención que a los cotizantes no les sea reconocido su rol en las empresas que sus aportes han creado. El poder de gobierno lo tienen los dueños de las administradoras, quedando sin voz los propietarios, y delegando en otros, los expertos, la administración de su patrimonio. Por lo mismo, la creación de estructuras de propietarios será útil en la medida que entreguen poder verdadero a los propietarios y no sean meras estructuras simbólicas y laterales.
En este contexto institucional y de crispación social con el sistema, han surgido algunas propuestas que buscan involucrar a los cotizantes en el gobierno corporativo de los fondos. En esta línea, se encuentra la propuesta del titular de la Superintendencia de Pensiones en el sentido de incorporar representantes elegidos de los cotizantes en la administración de los fondos de pensiones (Macías, 2016). También está la iniciativa del grupo Mejores Pensiones para Chile, que propone crear un Comité de Propietarios de Fondos en cada AFP y que entre sus funciones podría contratar evaluaciones sobre la calidad de los servicios prestados a los afiliados, incluyendo la gestión financiera, los servicios administrativos y las comisiones cobradas. La elección de sus integrantes sería por sorteo entre afiliados de la AFP dada la imposibilidad de votación (probable alta abstención) y la posibilidad de captura de que podrían ser objeto (Grupo Mejores Pensiones para Chile, 2016).

\section{Legitimidad, la piedra filosofal del sistema de AFP}

Más allá de las buenas prácticas en materia de gobierno corporativo, un sistema de esta naturaleza requiere tener validez social, es decir, ser reconocido y aceptado como lícito y genuino por el conjunto de partes involucradas (cotizantes, pensionados, administradoras, empleadores, especialistas, etc.) Lo anterior, es tal vez el asunto menos considerado al momento de diseñar reformas para nuestro sistema de pensiones.

La construcción de un fondo de pensiones, como parte de un sistema de protección social, pide la renuncia a una parte de los ingresos presentes con la promesa de bienestar futuro. Supone que cada sujeto realiza una suerte de transacción interna que concluye en una aceptación consciente y razonada de un sacrificio. Sin embargo, hoy sabemos que cuando las penurias afectan a todos son mejor aceptadas que cuando son particulares. Consistentemente, estudios evidencian que la percepción negativa respecto de la industria de las AFP se ve reforzada en los períodos de rentabilidad negativa de los fondos y en que sus administradores mantienen utilidades (Consejo Asesor Presidencial para la Reforma Previsional, 2006). De su lado, cuando se propone aumentar la contribución del empleador, no hay que olvidar que las empresas siempre preferirán remunerar a sus trabajadores por desempeño, cuando no hay vínculos aparentes o directos entre la provisión de beneficios por parte del empleador, el desempeño laboral específico de los trabajadores y los ingresos reportados de la empresa (Clark y Urwin, 2011).

El tema sigue siendo cómo aumentar el compromiso y preocupación de los afiliados con su fondos de pensión, 
en esta línea existen algunas ideas, desde los aportes de la conducta del consumidor, que proponen hacer real en el presente los resultados futuros, por ejemplo, permitiendo girar una pequeña porción de la rentabilidad que han tenido los ahorros o que parte de la comisión cobrada sea reintegrada en una cuenta de ahorro complementaria (Hidalgo, Manzur y Martínez, 2008). De esta forma, se piensa que aumentaría la percepción positiva respecto del esfuerzo presente y el involucramiento de los afiliados con el sistema.

Cualquier reforma deberá considerar que los resultados de diferentes estudios revelan una baja valoración de la industria de las AFP y el sistema de pensiones en general. Es así como un estudio incluido en el informe de la Comisión Marcel constata que cerca del $50 \%$ de los encuestados califica al sistema de pensiones como malo o muy malo (Consejo Asesor Presidencial para la Reforma Provisional, 2006). Este rechazo puede deberse en alguna medida a la gestión del sistema por administradores privados, en circunstancias que se declara consistentemente que el sistema previsional debería ser de responsabilidad, al menos en parte, del Estado. Una década después, la encuesta encargada por la Comisión Bravo revela, en consistencia con los resultados ya presentados, que las frases que generan mayor nivel de acuerdo son: "las bajas pensiones son responsabilidad de las AFP", "el Estado debe hacerse cargo de las pensiones a través de impuestos" $y$ "las bajas pensiones son responsabilidad del Estado" (Comisión Asesora Presidencial sobre el Sistema de Pensiones, 2015).

El rechazo antes descrito se combina con la desconfianza que muchos trabajadores manifiestan respecto del sistema. Esta desconfianza puede tener relación tanto con el origen autoritario de la reforma, que incluye el contexto político en que fue implementada, como con la manera en que se produjo la incorporación de los trabajadores activos al sistema de AFP. Como sea, nos encontramos con escepticismo o abierto rechazo a la administración privada de los fondos de pensiones. Estudios de la Comisión Bravo evidenciaron que las instituciones que menos confianza suscitaron fueron AFP (45\%), ISAPRE (47\%), Congreso (51\%) y Partidos Políticos (63\%) (Comisión Asesora Presidencial sobre el Sistema de Pensiones, 2015).

\section{Comentarios finales}

Un sistema de pensiones podrá funcionar en la medida que sea capaz de recoger las necesidades, aspiraciones y valores de los miembros de la sociedad en que se despliega. Da la impresión de que en nuestro país existen componentes de carácter social, histórico y cultural que condicionan las creencias y actitudes de las personas hacia un rechazo a la intervención de instituciones privadas con fines de lucro en las políticas públicas, a la que no escapa la previsión.

Hasta ahora las reformas han puesto énfasis en la eficiencia técnica de las soluciones, sin considerar del todo la necesidad de legitimidad y acuerdo de los diferentes actores de nuestra sociedad. Recién ahora se comienza a considerar la implicación o involucramiento de los propietarios de los fondos, buscando así devolver la vigencia al sistema. Da la impresión que los dispositivos parciales no serán suficientes en el escenario descrito, y que hace falta renovar un contrato social que devuelva la confianza entre actores y la cohesión social.

\section{Referencias}

Clark, G. y Urwin, R. (2011). DC pension fund best-practice design and governance. Benefits Quarterly. Fourth Quarter 2011: 36-49.

Consejo Asesor Presidencial para la Reforma Provisional (2006). Presentación para Mesa Redonda FIAP. Buenos Aires, 7 de Agosto 2006.

Grupo Mejores Pensiones para Chile (2016) El descontento con las pensiones: 7 conclusiones y 12 propuestas. Documento de trabajo, noviembre. Pontificia Universidad Católica de Chile.

Macías, O. (2016) APP, fondos de pensiones y gobierno corporativo: Resultados y desafíos. Presentación en el seminario"AFP y Gobierno Corporativo: logros y desafíos". Santiago, Agosto, 2016.

Superintendencia de Pensiones (2016) Informe Participación de las AFPy la AFC en Juntas y Asambleas. Enero - Mayo de 2016.

Comisión Asesora Presidencial sobre el Sistema de Pensiones (2015) Capítulo 6: La opinión y percepción del Sistema de Pensiones en Chile. Santiago.

Hidalgo, P; Manzur, E.y Martínez, C. (2008) Las administradoras de fondos de pensiones: análisis desde el punto de consumidor. Facultad de Economía y Negocios. U. de Chile. 